\title{
Keterkaitan Pasar Modal di Amerika Serikat, Indonesia Dan Korea Selatan Syamsul Hadi ${ }^{1}$
}

\author{
Fakultas Ekonomi dan Bisnis, Universitas Muhammadiyah Malang ${ }^{1}$
}

\begin{abstract}
Abstrak
Hasil analisis yang telah dilakukan maka dapat ditarik kesimpulan bahwa pasar modal Indonesia, Korea Selatan dan Amerika memiliki keterkaitan yang erat. Pasar modal Indonesia memiliki hubungan yang kuat dengan pasar modal di Amerika Serikat, sedangkan hubungan antara pasar modal Indonesia dengan pasar modal Korea Selatan lebih kecil jika dibandingkan dengan hubungan pasar modal Amerika Serikat.
\end{abstract}

Kata Kunci: Pasar modal; hubungaan antar pasar modal;

\section{Pendahuluan}

Pemulihan ekonomi Amerika Serikat (USA) ditandai penyerapan tenaga kerja oleh pasar domestik diawal tahun 2015 terus berlanjut, bank sentral USA (FED) bersikap menunggu efek lebih lanjut yaitu berupa kenaikan tingkat inflasi, dengan demikian akan menjadi pertimbangan untuk menaikan tingkat suku bunga bank sentral naik 0,75\% bahkan bisa 2,125\% akhir tahun 2016. Ekonomi Amerika yang bergairah menyeret dollar di luar negeri untuk kembali ke Amerika . Sebagai negara terbesar perekonomian dan mata uang tersebar dalam perdangangan internasional membawa dampak (contangion effect) bagi negara berkembang, terlebih berlarut-larutnya penundaan pengumuman kenaikan suku bunga bank sentral yang perlu diimbangi oleh negara kecil guna mengerem capital outflow.

Penyebragan dollar USA kembali ke negara asal membawa dampak melemahnya nilai tukar seperti Rupiah Indonesia atau Won Korea. Rupiah di perdangankan terus melemah yang disebabkan banyak hal, baik luar maupun dalam negeri sendiri seperti adanya kecenderungan transaksi di dalam negeri dengan mata uang dollar. Berbagai paket deregulasi untuk menahan pelemahan rupiah belum efektif dan kurang diantisipasi jauh bulan sebelumnya akan terjadinya perang mata uang (war currency) akibat pertarungan produksen minyak terbesar Arab Saudi dan produksen baru amerika serta kekuatan baru dunia yaitu china. Data menunjukkan nilai rupiah terpuruk hingga 14.375 per dollar pada awal bulan September 2015.

Dampak pelemahan nilai tukar selanjutnya merembet pada sektor riil yang masih mengandalkan import, penurunan produksi industri-industri yang menjual sahamnya di bursa ditambah rendahnya kepercayaan masyarakat pada kemampuan pemerintahan mengakibatkan capital outflow pada pasar modal. Data transaksi investor asing menunjukkan net sale yang terus meningkat sehingga indeks harga saham gabungan mencapai titik rendah mendekati 4.300 pada bulan Agustus 2015.

Korea selatan sebagai negara mitra kuat dengan Bursa Efek Indonesia (BEI) dan memiliki skala platform ekonomi kemiripan dengan Indonesia juga mengalami hal yang sama. Untuk itu peneliti tertarik untuk mengungkap lebih jauh hubungan pasar uang dan pasar modal pada ketiga negara sekaligus dengan menempatkan USA sebagai negara yang memiliki hard currency dan perekonomian terbesar dan menempatkan korea sebagai negara setara Indonesia yang merasakan dampak penguatan nilai dollar, sekaligus mitra intensif bursa saham dikawasan ASEAN.

\section{Rumusan masalah dalam penelitian ini adalah:}

1. Bagaimana keterkaitan pasar uang terhadap pasar modal pada Amerika Serikat, Indonesia dan Korea Selatan?

2. Berapa besar efek nilai keterkaitan pasar uang terhadap pasar modal pada Amerika Serikat, Indonesia dan Korea Selatan?

\section{Tujuan Penelitian}

Adapun tujuan dari penelitian ini adalah:

\footnotetext{
${ }^{1}$ syam@umm.ac.id
} 
1. Menganalisis struktur keterkaitan pasar uang dan pasar modal pada USA, Indonesia dan Korea Selatan.

2. Mengetahui tingkat keterkaitan pasar uang dan pasar modal pada USA, Indonesia dan Korea Selatan.

\section{Metodologi}

Ruang Lingkup

Penelitian ini akan mengunakan data indeks Dow Jones, Indeks Harga Saham Gabungan, indeks Kospi, nilai tukar Rupiah/Dollar, nilai tukar Dollar/Won, nilai tukar Won/Rupiah pada kurun waktu Juli 2014Desember 2015.

\section{Metode Analisis Data}

Data yang terkumpul selanjutnya akan diolah dan disajikan dalam bentuk matrix correlations sehingga dapat dilakukan analisis untuk mengambarkan struktur keterkaitan masing masing variabel.

1. Analisis Diskriptif

Analisis diskriptif adalah metode atau cara mendeskripsikan, menggambarkan, menjabarkan, atau menguraikan data sehingga mudah dipahami. Analsis deskriptif mengacu pada bagaimana menata atau mengorganisasi data, menyajikan, dan menganalisis data. Menata, menyajikan, dan menganalisis data dapat dilakukan dengan menentukan nilai rata-rata hitung, median, modus, standar deviasi, dan persen/proporsi. Atau untuk menggambarkan data adalah dengan membuat tabel, distribusi frekuensi, dan diagram atau grafik

2. Analisis Ekonometrik

Analisis ekonometrik digunakan untuk mengetahui hubungan indeks Dow Jones, Indeks Harga Saham Gabungan, indeks Kospi, nilai tukar Rupiah/Dollar, nilai tukar Dollar/Won, nilai tukar Won/Rupiah. secara matematis model formulasinya adalah sebagai berikut:

Koefisien korelasi ;

$\left.r=\left(\sum N \cdot \sum X Y\right)-\left(\sum X \cdot \sum Y\right)\right] / \sqrt{\left\{\left[\left(N \cdot \sum X 2\right)-\left(\sum X\right) 2\right] \cdot\left[\left(N \cdot \sum Y 2\right)-\left(\sum Y\right) 2\right]\right\}}$

Dimana

$\mathrm{r}=$ koefisien korelasi

$\mathrm{X}=$ variabel $\mathrm{x}$

$\mathrm{Y}=$ variabel $\mathrm{y}$

\section{Hasil dan Pembahasan}

Penelitian ini menggunakan data bulanan harga penutupan Dow Jones Industrial Average (DJIA) adalah satu indeks pasar saham yang didirikan oleh editor the wall street journal dan pendiri Dow Jones dan Company Charles Dow. Dow membuat indeks ini sebagai suatu cara untuk mengukur performa komponen industri di pasar saham Amerika. Saat ini DJIA merupakan indeks saham AS tertua yang masih berjalan. Bursa saham ini terdiri dari 30 perusahaan terbesar di AS yang sudah secara luas go publik. Untuk mengkompensasi efek pemecahan saham dan penyesuaian lainnya, sekarang ini menggunakan weighted average. Bukan rata rata actual dari harga saham komponenya.

KOSPI ( Korea Composite Stock Indeks ) di perkenalkan pada tahun 1983 dengan nilai dasar 100 pada tanggal 4 januari 1980. Kospi adalah indeks harga saham untuk saham biasa yang di perdagangkan di bursa saham korea (KSE). Indeks ini merupakan refresentatif dari indeks harga saham di korea selatan. Indeks ini di hitung berdasarkan kapitalisasi pasar.

Indeks Harga Saham Gabungan (IHSG) dan beberapa harga saham yang mewakili bursa dunia yang sudah di jelaskan sebelumnya. IHSG/JCI (Jakarta Composite Index) merupakan salah satu indeks harga saham yang di gunakan Bursa Efek Indonesia (BEI; dahulu bursa efek Jakarta (BEJ)). Di perkenalkan pertama kali pada tanggal 1 April 1983 sebagai indicator pergerakan harga saham di BEJ, indeks ini mencakup pergerakan harga seluruh saham biasa dan saham preferen yang tercatat di BEI. Hari dasar untuk perhitungan IHSG adalah tanggal 10 Agustus 1982. Indeks di tetapkan pada tanggal tersebut dengan nilai dasar 100 dan saham tercatat berjumlah 13 saham.

Seperti yang telah dijelaskan sebelumnya, penelitian ini menggunakan data times series pada periode Juli 2014 sampai dengan Desember 2015, sehingga terdapat 18 observasi secara keseluruhan.

Adapun korelasi sederhana masing-masing variabel yang digunakan dalam model penelitian ini dapat dilihat pada table 2 .

Tabel 2. Korelasi Sederhana

\begin{tabular}{|l|l|l|l|}
\hline Correlations & \multicolumn{4}{|l|}{} \\
\hline & DJIA & KOSP & IHSG \\
\hline Pearson Correlation & 1 & $.921^{* *}$ & $.826^{* *}$ \\
\hline
\end{tabular}




\begin{tabular}{|l|l|l|l|}
\hline Sig. (2-tailed) & & .000 & .000 \\
\hline $\mathrm{N}$ & 18 & 18 & 18 \\
\hline Pearson Correlation & $.921^{* *}$ & 1 & $.943^{* *}$ \\
\hline Sig. (2-tailed) & .000 & & .000 \\
\hline $\mathrm{N}$ & 18 & 18 & 18 \\
\hline Pearson Correlation & $.826^{* *}$ & $.943^{* *}$ & 1 \\
\hline Sig. (2-tailed) & .000 & .000 & \\
\hline $\mathrm{N}$ & 18 & 18 & 18 \\
\hline $\begin{array}{l}* * . \text { Correlation is significant at the 0.01 level (2- } \\
\text { tailed). }\end{array}$ \\
\hline
\end{tabular}

Sumber: SPSS, diolah sendiri 2016

Hubungan yang signifikan antara IHSG dengan DJIA membuktikan bahwa hipotesis pertama di terima. Hal ini sesuai dengan apa yang di kemukakan oleh Jeina Malangkay (2013) yang menyatakan bahwa DJIA berpengaruh positif dan signifikan terhadap IHSG. Pengaruh positif menunjukan bahwa akan semakin tinggi DJIA akan semakin meningkatkan IHSG, hal ini karena Amerika merupakan tujuan negara ekspor utama Indonesia sehingga perubahan kondisi perekonomian Indonesia di Amerika yang tercermin dalam DJIA akan memberikan pengaruh pada DJIA terhadap IHSG mengindikasikan telah terintegrasi pasar modal Indonesia dengan pasar modal Amerika Serikat. Terbukti integrasi antara Amerika Serikat dengan Indonesia sebesar 0,826. Itus udah menunjukkan integrasi yang tinggi antara Indonesia dengan Amerika Serikat.

Hipotesis kedua di terima dikarenakan ada hubungan yang signifikan antara IHSG dengan KOSPI. Hal ini sejalan dengan apa yang di teliti oleh Erman Deni Arfianto (2004) bahwa menunjukkan adanya integrasi antar pasar modal di Asia Pasifik dan peningkatan derajat integrasi antar pasar. Sedangkan pada periode- periode awal setelah shock, pasar modal-pasar modal yang secara geografis saling berdekatan mempunyai pengaruh yang cukup besar. Maka dari itu keterkaitan antara IHSG dengan KOSPI terintegrasi di karenakan ada beberapa faktor yang mempengaruhi di antaranya perdagangan ekspor dan impor antara Indonesia dengan Korea Selatan cukup tinggi. Sehingga keterkaitan antara kedua negara itu juga cukup tinggi. Hal ini terbukti dengan korelasi sederhana sebesar 0,943. Itu sudah menunjukkan bahwa integrasi Indonesia dengan kospi sangat tinggi, baik jangka pendek maupun panjang. Selain itu juga adanya hubungan bilateral kedua Negara yang terjalin dengan sangat baik serta perdagang anantar kedua Negara yang semakin meningkat dengan adanya pemerintahan baru.

\section{Kesimpulan dan Saran}

Berdasarkan hasil analisis yang telah dilakukan maka dapat ditarik kesimpulan bahwa pasar modal Indonesia, Korea Selatan dan Amerika memiliki keterkaitan yang erat. Pasar modal Indonesia memiliki hubungan yang kuat dengan pasar modal di Amerika Serikat, sedangkan hubungan antara pasar modal Indonesia dengan pasar modal Korea Selatan lebih kecil jika dibandingkan dengan hubungan pasar modal Amerika Serikat. Dengan kesimpulan yang ada maka saran yang akan disampaikan yaitu kepada pemerintah agar dapat menjalin kerja sama yang baik dengan negara-negara mitranya agar berdampak positif kepada pasar modal Indonesia.

\section{Ucapan Terimakasih}

Dengan menyebut nama Allah SWT yang Maha Pengasih lagi Maha Panyayang, Kami panjatkan puji syukur atas kehadirat-Nya, yang telah melimpahkan rahmat, hidayah, dan inayah-Nya kepada kami, sehingga kami dapat menyelesaikan penelitian dengan judul Keterkaitan Pasar Modal Di Amerika Serikat, Indonesia Dan Korea Selatan. Peneleitian ini telah kami susun dengan maksimal sehingga kami dapat menyelesaikan dalam kurun waktu yang telah ditentukan. Kami menyadari sepenuhnya bahwa masih ada kekurangan baik dari segi susunan kalimat maupun tata bahasanya. Oleh karena itu dengan tangan terbuka kami menerima segala saran dan kritik dari pembaca agar kami dapat memperbaiki penelitian ilmiah ini. Akhir kata kami berharap semoga penelitian ini dapat memberikan manfaat maupun inpirasi terhadap pembaca. 


\section{Referensi}

1. Adiningsih, Sri dkk. 1998. Perangkat Analisis dan Teknik Analisis Investasi di Pasar Modal Indonesia. Jakarta : PT. Bursa Efek Jakarta.

2. Alwi, Iskandar . 2003. Pasar Modal, Teori dan Aplikasi. Jakarta : Nasindo Internusa.

3. Ang, Robert. 1997. Buku Pintar Pasar Modal Indonesia, Edisi 1, Mediasoft Indonesia.

4. Anoraga, Panji dan Pakarti, Piji. 2001. Pasar Modal, Keberadaan dan Manfaatnya Bagi Pembangunan. Jakarta : PT. Rineka Cipta.

5. Avonti, Amos Amoroso dan Prawoto, Hudi, 2004. Analisis Pengaruh Nilai Tukar Rupiah/ US\$ Akuntansi Bisnis, Vol. III No. 5 September.

6. Bank Indonesia, 2002 - 2007, Indonesia Financial Statistik, BI, Jakarta.

7. Boediono. 1988. Ekonomi Moneter. Edisi Ketiga. BPFE, Yogyakarta.

8. Bursa Efek Indonesia (BEI). 2011. Laporan Harga Saham Bank Perbankan. http://www.idx.co.id.

9. Dheny. 2009. Analisis Pengaruh Suku Bunga, Volume Perdagangan dan Kurs terhadap Return Saham Sektor Properti yang Listed di BEI (Periode 2003-2007) [Tesis]. Semarang : Universitas Diponegoro.

10. Donna. 2009. Pengaruh Nilai Tukar Rupiah, Suku Bunga SBI, Volume Perdagangan Saham, Inflasi dan Beta Saham terhadap Harga Saham [Tesis]. Fakultas Ekonomi Universitas Diponegoro. Semarang.

11. Novianto. Aditya. 2008. Analisis Pengaruh kurs rupiah, tingkat suku bunga SBI, terhadap IHSG periode 2003-2007.

12. Pananda Pasaribu, Wilson R. L. Tobing, Adler H. Manurung. 2009. Analisis Pengaruh Inflasi, dan Tingkat Suku BUnga SBI terhadap indeks Hrga Saham LQ-45 di Bursa Efek Indonesia Periode 2000 $-2010$

13. Rumiris L. Tobing. 2009. Pengaruh Inflasi, Nilai Tukar dan Tingkat Suku Bunga Terhadap Harga Saham Perbankan Yang Terdaftar di Bursa Efek Indonesia (BEI). 